\title{
Lesão medular associada ao manejo incorreto de caprino
}

\author{
Medular lesion associated to caprine management \\ Fernanda Moraes Cardoso ${ }^{1}$, Pedro Miguel Ocampos Pedroso ${ }^{1}$, Adriana da Silva Santos ${ }^{1}$, \\ Marcele Sousa Vilanova ${ }^{2}$, David Driemeier ${ }^{1} \&$ Verônica Schmidt ${ }^{1}$
}

\begin{abstract}
RESUMO
Práticas inadequadas de manejo atuam como fatores predisponentes a quadros clínico-patológicos em caprinos, destacando-se as falhas nutricionais e erros de amochamento e casqueamento. No presente relato, apresenta-se um caso de traumatismo medular na região cervical em caprino Saanen de quatro anos de idade, mantido em regime de confinamento. Segundo história clínica obtida com o tratador, o caprino se apresentou disposto no arraçoamento matinal, entretanto, ao entardecer mostrou-se apático e em decúbito esternal, permanecendo assim por cinco dias. No exame clínico, verificou-se que o animal não conseguia levantar-se, mas mantinha apetite e resposta aos estímulos externos normais. Optou-se pela realização da eutanásia, em decorrência do estado debilitado em que se apresentava. No exame macroscópico, evidenciou-se hemorragia na porção cervical da medula espinhal (C4-C6) e, no exame microscópico, observou-se, na medula cervical, hemorragia e hemossiderose difusa moderada, degeneração axonal e esferóides axonais. Determinou-se que o quadro apresentado era compatível com traumatismo medular na região cervical. Após avaliação das instalações e manejo adotados na propriedade, considera-se a possibilidade do macho ter escorregado enquanto se alimentava, ficando com os chifres presos à proteção do cocho, o que levou à lesão na medula. Considera-se, assim, que a manutenção adequada das estruturas produtivas é fundamental ao bom desempenho e à sanidade dos animais.
\end{abstract}

Descritores: caprino, lesão medular, traumatismo.

\section{ABSTRACT}

Inadequate management practices function as predisposing factors in clinical-pathological profiles of caprines, highlighting nutritional mistakes and dehorning, as well as hoof-trimming errors. In this report, a case of medullary traumatism at cervical region in a four-year old Saanen caprine kept in confinement is presented. According to the clinical history obtained from the keeper, the animal was vivacious at the morning feed; however, at nightfall, it was apathetic and on sternal decubitus, thus remaining for five days. During clinical examination, it was observed that the animal was not able to stand up; nonetheless, it kept its appetite and response to normal external stimuli. Euthanasia was chosen due to the debilitating condition of the animal. During macroscopic examination, hemorrhage in the cervical portion of the medullary spine (C4-C6) was noted, whereas during microscopic examination it was observed hemorrhage and moderate diffuse haemosiderosis in the cervical medulla, axonal degeneration and axonal spheroids. It was determined that the presented profile was compatible with medullary traumatism in the cervical region. After evaluation of the facilities and management adopted in the property, it was considered possible that the male slipped whilst feeding, becoming stuck by its horns in the trough cover, leading to medullary lesion. Therefore, an adequate maintenance of the productive structures is fundamental for the good performance and sanity of the animals.

Keywords: caprine, medullary lesion, traumatism 


\section{INTRODUÇÃO}

A adoção de práticas inadequadas de manejo em caprinos pode comprometer o sistema produtivo e desencadear quadros clínicos e perdas econômicas, inclusive de animais do plantel. Entre estas, destacamse falhas nutricionais e no manejo do recém-nascido, erros de amochamento e casqueamento, entre outros.

Em vista da ocorrência de um caso clínico relacionado ao manejo de cascos e instalações, o qual resultou no óbito do animal, entendemos que o relato do mesmo seja importante para alertar produtores e técnicos quanto à necessidade de observar o manejo, na busca da melhor produtividade.

\section{RELATO}

Um caprino macho, da raça Saanen, com quatro anos de idade, criado em sistema de confinamento, apresentou-se disposto durante o arraçoamento da manhã. No segundo fornecimento de alimento, o tratador percebeu que o animal permaneceu em decúbito esternal, não respondendo às tentativas de levantá-lo. $\mathrm{O}$ animal assim permaneceu por cinco dias, quando foi solicitado atendimento clínico ao animal. Realizouse o exame clínico e verificou-se que o animal não

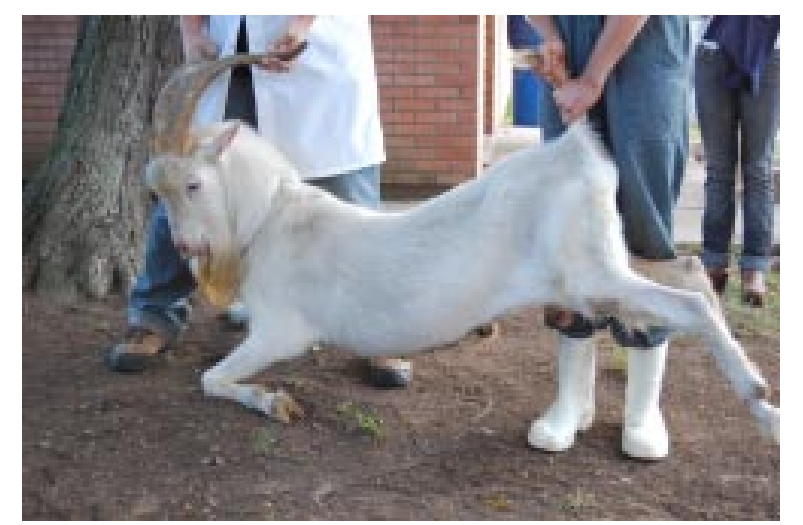

Figura 1. Caprino macho adulto impossibilitado de manter-se em estação.

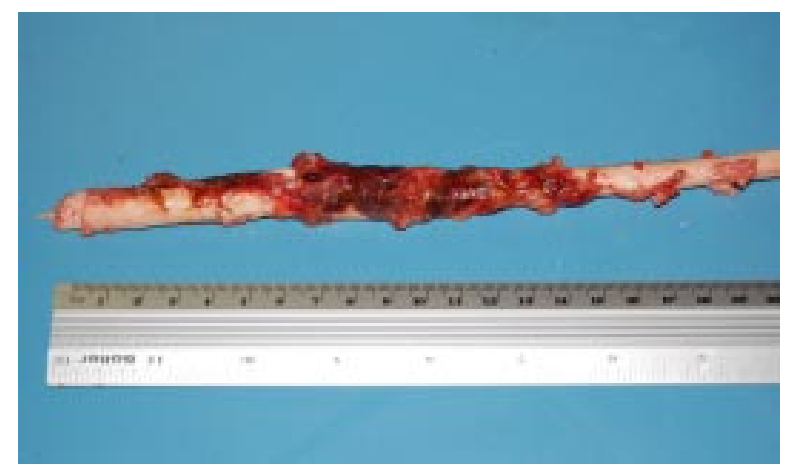

Figura 2. Presença de hemorragia na porção cervical (C4 e C6) da medula espinhal de um caprino. conseguia levantar-se, mas mantinha o apetite e resposta aos estímulos externos normais. Observou-se, ainda, que o animal apresentava crescimento excessivo dos cascos. Em decorrência do estado debilitado do animal e por esse não conseguir mais permanecer em estação foi realizada a eutanásia, de acordo com as recomendações da Resolução ${ }^{\circ} 714$ do Conselho Federal de Medicina Veterinária do Brasil [3]. Durante a necropsia fragmentos de diversos órgãos foram coletados e fixados em formol $10 \%$, processados de forma rotineira para histologia, incluídos em parafina, cortados a 5 micras de espessura e corados pela técnica de hematoxilina e oosina (HE) [5]. Adicionalmente, foram encaminhados fragmentos de pulmão, fígado e baço para pesquisa de micro-organismos [6].

No exame macroscópico evidenciou-se hemorragia na porção cervical (C4 e C6) da medula espinhal e pulmão não colapsado e com formações nodulares multifocais nos lóbulos. Os demais órgãos não apresentavam alterações macroscópicas de significado.

Ao exame microscópico, observou-se, na medula cervical hemorragia e hemossiderose difusa moderada, degeneração axonal e esferóides axonais. Os demais órgãos não apresentavam alterações histológicas. Pulmão com infiltrado granulomatoso com células gigantes multifocal acentuado, associado a ovos e larvas de parasitas no parênquima pulmonar, além de hiperplasia multifocal moderada da parede muscular de bronquíolos e enfisema crônico.

Com base no histórico e nos achados macroscópicos e microscópicos, determinou-se como diagnóstico: lesão medular na região cervical em decorrência de traumatismo.

Casos de lesão vertebral, na região cervical, em caprinos, embora não sejam frequentemente relatados, foram descritos associados a traumas [1 e 4].

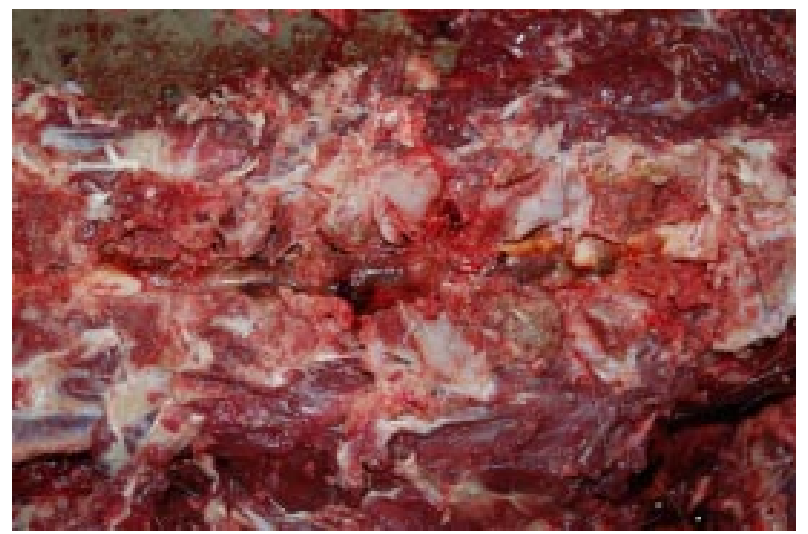

Figura 3. Medula espinhal de caprino com presença de hemorragia. 
Diferentemente do quadro clínico no presente caso, em cinco casos de lesão do segmento cervical vertebral [1] foi observado decúbito lateral permanente com incapacidade de adotar o decúbito esternal voluntariamente, tetraparesia e hiperreflexia. Já, na Paraíba, 6,34\% dos casos de sintomatologia nervosa estavam associados a trauma [4].

Para identificar os fatores que teriam levado à lesão, retornou-se à propriedade e, juntamente com o tratador, observaram-se as instalações e o comportamento dos demais animais do plantel. Verificou-se que a prática de casqueamento, embora realizada, não atende satisfatoriamente a todos os animais. $\mathrm{O}$ casqueamento preventivo é uma prática importante a ser adotada em sistemas produtivos, uma vez que o caprino precisa de membros fortes e bem aprumados, tanto para a busca por alimento quanto na atividade reprodutiva [2].

Observou-se, ainda, que na baia onde o macho era mantido, havia sido colocada uma proteção de madeira sobre o cocho para evitar que o mesmo pulasse para fora da baia. $\mathrm{O}$ adequado planejamento e a concepção das instalações são importantes à produção de caprinos leiteiros, estando entre os objetivos das instalações a contenção adequada dos animais [7]. Observando-se o outro macho da propriedade, em instalações com condições semelhantes, verificou-se que o mesmo colocava os chifres entre a proteção e a parede da baia para alimentar-se. Considerando-se que condições de manejo, como pisos escorregadios, podem predispor à ocorrência de fraturas [8] e traumas, verificou-se que o piso ripado de madeira permanecia molhado, por água ou urina, tornando-se escorregadio. Desta forma, é possível que o macho tenha escorregado enquanto se alimentava, ficando com os chifres presos à proteção o que o levou à lesão na medula.

$\mathrm{O}$ manejo inadequado pode causar perdas no rebanho caprino [4], sendo que a manutenção das estruturas produtivas é fundamental ao bom desempenho produtivo dos animais.

\section{REFERÊNCIAS}

1 Borges A.S., Silva D.P.G., Gonçalves R.C., Chiacchio S.B., Amorim R.M., Kuchembuk M.R.G., Vulcano L.C., Bandarra E.P. \& Lopes R.S. 2003. Fraturas vertebrais em grandes animais: estudo retrospectivo de 39 casos (1987-2002). Arquivo Brasileiro de Medicina Veterinária e Zootecnia. 55 (2). [Fonte: <http://www.scielo.br/scielo.php>].

2 Brito M.A. 2007. Cascos saudáveis. Caprinforma: Edição Especial Expointer, n. 4, p. 5-6. [Fonte: 〈http://www.caprisul.com.br〉].

3 CFMV - Conselho Federal de Medicina Veterinária do Brasil. 2002. Resolução №. 714, de 20 de junho de 2002. Procedimentos e métodos de eutanásia em animais. 6p.

4 Guedes K.M.R., Riet-Correa F., Dantas A.F.M., Simões S.V.D., Neto E.G.M., Nobre V.M.T. \& Medeiros R.M.T. 2007. Doenças do sistema nervoso central em caprinos e ovinos no semi-árido. Pesquisa Veterinária Brasileira. 27: 29-38.

5 Prophet E.B., Mills B., Arrington J.B. \& Sobin L.H. 1992. Laboratory Methods in Histotechnology. Washington: American Registry of Pathology, 279p.

6 Quin P.J., Carter M.E., Markey B. \& Carter G.R. 1998. Clinical Veterinary Microbiology. London: Mosby International, p. 144-151.

7 Ribeiro S.D.A. 1997. Caprinocultura: Criação Racional de Caprinos. São Paulo: Nobel. 318 p.

8 Sherman D.M. 1987. Localized diseases of the bovine brain and spinal cord. Veterinary Clinics of North America: Food Animal Practice. 3: 179-191.

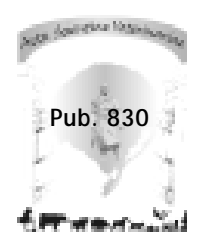

